\title{
Treatment and Mortality in Men with Localized Prostate Cancer: A Popu- lation-Based Study in California
}

\author{
Weiva Sieh ${ }^{1, *}$, Daphne Y. Lichtensztajn ${ }^{2}$, David O. Nelson ${ }^{2}$, Myles Cockburn $^{3}$, Dee W. West ${ }^{1,2}$, \\ James D. Brooks ${ }^{4, \dagger}$ and Ellen T. Chang ${ }^{1,2, \dagger}$ \\ ${ }^{1}$ Division of Epidemiology, Department of Health Research and Policy, Stanford University School of Medicine, Stan- \\ ford, CA, USA \\ ${ }^{2}$ Cancer Prevention Institute of California, Fremont, CA, USA \\ ${ }^{3}$ Department of Preventive Medicine, University of Southern California School of Medicine, Los Angeles, CA, USA \\ ${ }^{4}$ Department of Urology, Stanford University School of Medicine, Stanford, CA, USA
}

\begin{abstract}
Purpose: To provide patients and physicians with population-based estimates of mortality from prostate cancer or other causes depending upon the primary treatment modality, stratified by patient age, tumor stage and grade.

Methods: We conducted a 10-year competing-risk analysis of 45,440 men diagnosed with clinically localized (T1 or T2) prostate cancer in California during 1995-1998. Information on patient characteristics, primary treatment and cause of death was obtained from the California Cancer Registry.

Results: In this population-based cohort, the most common primary treatment was surgery (40.4\%), followed by radiotherapy (29.1\%), conservative management (20.8\%), and androgen deprivation therapy (ADT) monotherapy (9.8\%). Prostate cancer mortality differed significantly $(\mathrm{p}<0.0001)$ across treatment groups among patients $<80$ years at diagnosis with moderately or poorly differentiated disease; the 10-year disease-specific mortality rates were generally highest for men treated with ADT monotherapy [range: $3.3 \%(95 \% \mathrm{CI}=0.8-12.5 \%)$ to $53.8 \%(95 \% \mathrm{CI}=34.4-72.2 \%)$ ], intermediate for men treated with conservative management [range: $1.7 \%(95 \% \mathrm{CI}=0.7-4.6 \%)$ to $30.0 \%(95 \% \mathrm{CI}=16.2-48.8 \%$ ] or radiotherapy [range: $3.2 \%(95 \% \mathrm{CI}=1.8-5.5 \%)$ to $18.3 \%(95 \% \mathrm{CI}=15.1-22.0 \%)$ ], and lowest for men treated with surgery [range: $1.2 \%(95 \% \mathrm{CI}=0.8-1.7 \%)$ to $11.0 \%(95 \% \mathrm{CI}=8.4-14.2 \%)$ ].

Conclusion: The cause-specific mortality estimates provided by this observational study can help patients and physicians better understand the expected long-term outcomes of localized prostate cancer given the initial treatment choice and practice patterns in the general population.
\end{abstract}

Keywords: Prostate cancer, treatment, mortality, cohort study, California Cancer Registry.

\section{INTRODUCTION}

Over the past two decades, widespread application of prostate specific antigen (PSA) testing has shifted the clinical landscape of prostate cancer to earlier stages of the disease [1].

In 2012, over 241,000 U.S. men were diagnosed with prostate cancer, approximately $80 \%$ of whom had localized (stage T1 or T2) disease [2]. To date, randomized trials have shown little survival benefit with PSA testing, indicating that many indolent tumors are being overdetected and overtreated $[3,4]$. The optimal treatment of localized prostate cancer

\footnotetext{
*Address correspondence to this author at the Department of Health Research and Policy, Stanford University School of Medicine, HRP Redwood Building, Room T254B, 259 Campus Drive, Stanford, CA 943055405, USA; Tel: (650) 723-6910; Fax: (650) 725-6951;

E-mail: wsieh@stanford.edu

${ }^{\dagger}$ These authors contributed equally.
}

remains controversial [5]. Standard treatment options include surgery, radiation, and conservative management (active surveillance or watchful waiting) [6]. Additionally, primary treatment with androgen deprivation therapy (ADT) is frequent despite lack of evidence from clinical trials to support its use as monotherapy for localized prostate cancer [7].

Randomized controlled trials are currently underway that will ultimately help determine whether or not treatment reduces mortality in men with localized prostate cancer. Observational studies have suggested that active surveillance of low-risk patients may be a safe alternative to initial treatment and may preserve quality of life [8]. However, recent results from randomized trials of radical prostatectomy compared with observation demonstrated that surgery significantly reduced prostate cancer mortality among men younger than 65 years at diagnosis [9] or high-risk disease [10], indicating that some patient subgroups may have a survival benefit from aggressive treatment. 
The natural history of prostate cancer is heterogeneous, and most men with localized prostate cancer will die of causes other than their disease [11]. Therefore, knowledge of a man's absolute risks of dying from prostate cancer versus other causes is critical for making informed treatment choices. We assembled a population-based cohort of 45,440 men representing virtually all men diagnosed with clinically localized prostate cancer in California during 1995-1998. Our aim was to describe the absolute 10-year mortality from prostate cancer or competing causes of death in patient populations initially treated with surgery, radiation, ADT monotherapy or conservative management.

\section{PATIENTS AND METHODS}

\section{Study Population}

We identified all men diagnosed with a first primary invasive adenocarcinoma of the prostate (International Classification of Diseases for Oncology, $3^{\text {rd }}$ edition [ICD-O-3] site code 61.9; morphology code 8140) in California between January 1, 1995 and December 31,1998 using data from the California Cancer Registry (CCR; http://www.ccrcal.org/), which captures $99 \%$ of cancer diagnoses state-wide. We chose the years 1995-1998 in order to obtain at least 10 years of follow-up, needed because of low disease-specific mortality among men with localized prostate cancer, and to represent the period following the introduction of PSA testing, when stage migration had largely stabilized [12]. Eligible patients were diagnosed with clinical stage T1 or T2 disease $(\mathrm{N}=55,082)$. Exclusion criteria included: ambiguous stage ("localized, not otherwise specified"; $\mathrm{N}=5111$ ); diagnosis on autopsy or death certificate only $(\mathrm{N}=46)$; "unknown" or "other" race $(\mathrm{N}=1799)$; unknown tumor grade $(\mathrm{N}=1097)$; lost to follow-up within 10 years $(\mathrm{N}=1119)$; invalid followup dates $(\mathrm{N}=1)$; and cause of death unavailable or unknown $(\mathrm{N}=358)$. We also excluded cases who received chemotherapy $(\mathrm{N}=111)$ within 4 months of diagnosis because chemotherapy is not standard treatment for localized prostate cancer and could reflect more advanced disease. The final study population consisted of 45,440 men. This study was approved by the Institutional Review Board of the Cancer Prevention Institute of California.

\section{Outcome Ascertainment}

The CCR regularly updates vital status information through hospital follow-up and linkages with state and national databases and agencies. Follow-up information was available through May 31, 2010; the median follow-up period was 138 months after diagnosis. Cases were classified as alive or deceased within 10 years of diagnosis. The cause of death was classified as prostate cancer or other competing causes based upon the underlying cause of death on the death certificate, which has been shown to be a reliable means of ascertaining death due to prostate cancer $[13,14]$.

\section{Patient Characteristics}

Patient diagnoses and demographic data are routinely collected by the CCR in accordance with guidelines of the National Cancer Institute (NCI) Surveillance, Epidemiology and End Results (SEER; http://seer.cancer.gov/) program and the California Department of Public Health. For this study, age at diagnosis was categorized in 10-year groups $(<50,50-59,60-69,70-79,80+)$. Tumor stage was categorized as American Joint Committee on Cancer (AJCC) stage T1 (clinically inapparent) or T2 (clinically apparent, confined to prostate) using the SEER clinical extent-of-disease information. Tumor grade was categorized as welldifferentiated (Gleason score 2-4), moderately differentiated (Gleason score 5-7), or poorly differentiated (Gleason score 8-10) as defined by SEER [15]. Race/ethnicity was categorized as non-Hispanic white, non-Hispanic black, Hispanic, or Asian/Pacific Islander [16]. Socioeconomic status (SES) was measured using a neighborhood-level index that incorporates Census data on education, income, occupation, and housing costs at the census block-group level [17]. Each case was assigned to his neighborhood SES quintile based on the distribution of the composite SES index across California.

The CCR collects information on the first course of treatment for prostate cancer that was administered or initiated within four months of diagnosis. Primary treatment was categorized as surgery, radiotherapy, ADT monotherapy, or conservative management (no therapy within four months of diagnosis). Surgery denotes procedures such as prostatectomy that ablate the organ; patients classified as having received surgery included those who also received adjuvant radiation and/or ADT. Radiotherapy denotes external beam radiation and/or brachytherapy; patients classified as having received radiotherapy included those who received both radiotherapy and ADT. ADT monotherapy denotes initial treatment with only hormone therapy or endocrine surgery (orchiectomy).

\section{Statistical Analysis}

Competing risks of death from prostate cancer or other causes were estimated for each of the four primary treatment groups, stratified by age, grade, and stage at diagnosis. $\mathrm{Cu}-$ mulative incidence functions were used to estimate the absolute risk of dying of either prostate cancer or other causes, and global tests of the equality of estimated mortality curves across treatment groups were performed using the cmprsk package $[18,19]$ implemented in R (R Foundation for Statistical Computing, Vienna, Austria). 95\% confidence intervals (CI) for 10-year cumulative mortality estimates were constructed using the delta method and log-odds transformation to obtain estimates between 0 and 1 [20]. We assessed the sensitivity of results to potential misclassification of clinical stage by comparing results in the surgery group overall to the subset of 9,665 surgically treated men with pathologically confirmed localized disease. All p-values were 2-sided.

\section{RESULTS}

As of May 31, 2010, 15,143 deaths had occurred among the 45,440 men diagnosed with clinically localized prostate cancer in California during 1995-1998, and 2,720 (18\%) of these deaths were attributed to prostate cancer (Table 1). About half of all cases had stage T2 disease at diagnosis and $11.7 \%$ of all tumors were well differentiated. The most common primary treatment was surgery $(40.4 \%)$, followed by radiation $(29.1 \%)$, conservative management $(20.8 \%)$, and ADT monotherapy (9.8\%). Among surgically treated patients, $644(3.5 \%)$ received adjuvant radiotherapy only, 
Table 1. Characteristics of California Men diagnosed with Clinically Localized Prostate Cancer in 1995-1998, Overall and by Primary Treatment

\begin{tabular}{|c|c|c|c|c|c|c|c|c|c|c|}
\hline \multirow[t]{2}{*}{ Characteristics } & \multicolumn{2}{|c|}{$\begin{array}{l}\text { All Cases } \\
\mathrm{N}=45,440\end{array}$} & \multicolumn{2}{|c|}{$\begin{array}{c}\begin{array}{c}\text { Conservative } \\
\text { Management }\end{array} \\
\mathrm{N}=9,435\end{array}$} & \multicolumn{2}{|c|}{$\begin{array}{c}\text { Surgery } \\
\mathrm{N}=18,355\end{array}$} & \multicolumn{2}{|c|}{$\begin{array}{c}\text { Radiation Therapy } \\
\qquad \mathrm{N}=13,203\end{array}$} & \multicolumn{2}{|c|}{$\begin{array}{c}\text { ADT Mono- } \\
\text { therapy } \\
\mathrm{N}=4,447\end{array}$} \\
\hline & $\mathrm{n}$ & $\%$ & $\mathrm{n}$ & $\%$ & $\mathrm{n}$ & $\%$ & $\mathrm{n}$ & $\%$ & $\mathrm{n}$ & $\%$ \\
\hline \multicolumn{11}{|l|}{10 -year survival } \\
\hline Alive & 30,297 & $(66.7)$ & 4575 & $(48.5)$ & 15412 & $(84.0)$ & 8651 & $(65.5)$ & 1659 & (37.3) \\
\hline Died of prostate cancer & 2,720 & $(6.0)$ & 611 & $(6.5)$ & 537 & (2.9) & 815 & $(6.2)$ & 757 & $(17.0)$ \\
\hline Died of other causes & 12,423 & $(27.3)$ & 4249 & $(45.0)$ & 2406 & $(13.1)$ & 3737 & $(28.3)$ & 2031 & $(45.7)$ \\
\hline \multicolumn{11}{|l|}{ Age at diagnosis (years) } \\
\hline$<50$ & 797 & $(1.8)$ & 64 & $(0.7)$ & 614 & (3.3) & 102 & $(0.8)$ & 17 & $(0.4)$ \\
\hline $50-59$ & 7,005 & $(15.4)$ & 654 & $(6.9)$ & 4798 & $(26.1)$ & 1309 & $(9.9)$ & 244 & (5.5) \\
\hline $60-69$ & 17,735 & $(39.0)$ & 2457 & $(26.0)$ & 9554 & $(52.1)$ & 4784 & $(36.2)$ & 940 & $(21.1)$ \\
\hline $70-79$ & 16,268 & $(35.8)$ & 4329 & $(45.9)$ & 3349 & $(18.2)$ & 6576 & $(49.8)$ & 2014 & $(45.3)$ \\
\hline $80+$ & 3,635 & $(8.0)$ & 1931 & $(20.5)$ & 40 & $(0.2)$ & 432 & (3.3) & 1232 & (27.7) \\
\hline \multicolumn{11}{|l|}{ Race/ethnicity } \\
\hline Non-Hispanic White & 34,218 & $(75.3)$ & 6838 & $(72.5)$ & 13881 & $(75.6)$ & 10156 & $(76.9)$ & 3343 & $(75.2)$ \\
\hline Non-Hispanic Black & 3,931 & $(8.7)$ & 922 & $(9.8)$ & 1466 & $(8.0)$ & 1150 & $(8.7)$ & 393 & $(8.8)$ \\
\hline Hispanic & 4,936 & $(10.9)$ & 1106 & $(11.7)$ & 2127 & $(11.6)$ & 1232 & (9.3) & 471 & (10.6) \\
\hline Asian/Pacific Islander & 2,355 & $(5.2)$ & 569 & $(6.0)$ & 881 & $(4.8)$ & 665 & $(5.0)$ & 240 & $(5.4)$ \\
\hline \multicolumn{11}{|l|}{ Neighborhood SES (quintile) } \\
\hline 1 (lowest) & 5,114 & $(11.3)$ & 1438 & $(15.2)$ & 1738 & $(9.5)$ & 1294 & $(9.8)$ & 644 & (14.5) \\
\hline 2 & 7,700 & $(16.9)$ & 1846 & $(19.6)$ & 2869 & $(15.6)$ & 2161 & $(16.4)$ & 824 & $(18.5)$ \\
\hline 3 & 9,144 & $(20.1)$ & 1953 & $(20.7)$ & 3461 & $(18.9)$ & 2784 & $(21.1)$ & 946 & (21.3) \\
\hline 4 & 10,415 & $(22.9)$ & 1989 & $(21.1)$ & 4324 & $(23.6)$ & 3116 & $(23.6)$ & 986 & $(22.2)$ \\
\hline 5 (highest) & 13,067 & $(28.8)$ & 2209 & $(23.4)$ & 5963 & $(32.5)$ & 3848 & $(29.1)$ & 1047 & (23.5) \\
\hline \multicolumn{11}{|l|}{ Gleason score, tumor grade } \\
\hline 2-4, well-differentiated & 5,330 & $(11.7)$ & 2515 & $(26.7)$ & 1016 & $(5.5)$ & 1423 & $(10.8)$ & 376 & $(8.5)$ \\
\hline $5-7$, moderately differentiated & 32,092 & $(70.6)$ & 5961 & $(63.2)$ & 13800 & $(75.2)$ & 9540 & $(72.3)$ & 2791 & $(62.8)$ \\
\hline $8-10$, poorly differentiated & 8,018 & $(17.6)$ & 959 & $(10.2)$ & 3539 & $(19.3)$ & 2240 & $(17.0)$ & 1280 & $(28.8)$ \\
\hline \multicolumn{11}{|l|}{ Clinical stage } \\
\hline $\mathrm{T} 1$ & 21,965 & $(48.3)$ & 5917 & $(62.7)$ & 9309 & $(50.7)$ & 4993 & $(37.8)$ & 1746 & (39.3) \\
\hline $\mathrm{T} 2$ & 23,475 & $(51.7)$ & 3518 & $(37.3)$ & 9046 & $(49.3)$ & 8210 & $(62.2)$ & 2701 & $(60.7)$ \\
\hline \multicolumn{11}{|l|}{ Adjuvant ADT use } \\
\hline No & 33,213 & $(73.1)$ & & & 15948 & $(86.9)$ & 7830 & $(59.3)$ & & \\
\hline Yes & 12,227 & $(26.9)$ & & & 2407 & $(13.1)$ & 5373 & $(40.7)$ & & \\
\hline
\end{tabular}

$\mathrm{ADT}=$ androgen deprivation therapy; SES $=$ socioeconomic status.

$2,157(11.8 \%)$ received adjuvant ADT only, and $250(1.4 \%)$ received both radiotherapy and ADT within four months of diagnosis. A substantially greater proportion of men who underwent primary radiotherapy received adjuvant ADT
$(40.7 \%)$ compared with men who underwent surgery (13.1\%).

Characteristics of patients in the four primary treatment groups are shown in Table 1. Patients who initially received 
Table 2. Sample Sizes by Age and Vital Status as of May 2010 Among California Men Diagnosed with Clinically Localized Prostate Cancer in 1995-1998.

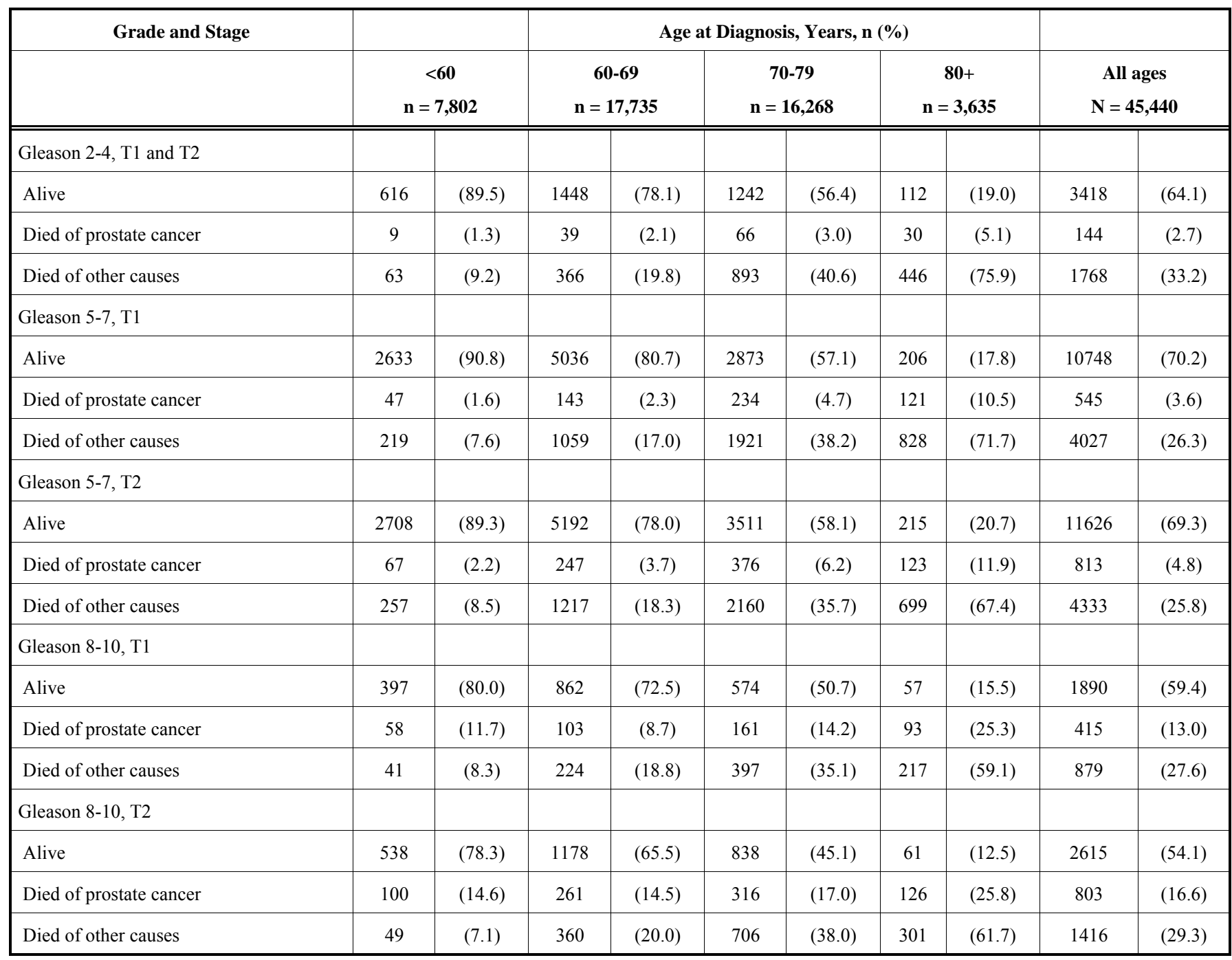

conservative management tended to be older (median age 73 years) at diagnosis, and to have well-differentiated and T1 disease. Surgically treated patients were youngest (median age 64 years) at diagnosis, and least likely to have welldifferentiated tumors at diagnosis. Patients treated with radiation were intermediate to the other treatment groups with respect to age (median 70 years) at diagnosis and tumor grade, but were the most likely to have T2 disease at diagnosis. Patients who received ADT monotherapy were the oldest (median age 75 years) at diagnosis, and most likely to have poorly differentiated tumors.

Table 2 shows the sample size and proportion of the 45,440 men with clinically localized prostate cancer that died from their disease or other causes, stratified by age at diagnosis, tumor grade and stage. In general, men with localized prostate cancer were far more likely to die from other causes than from their disease, except for men $<60$ years diagnosed with poorly differentiated disease. As expected, the proportion of men who died from prostate cancer generally increased with older age, higher grade, and clinically apparent disease at diagnosis. The 10-year cumulative mortality rate among all men with localized prostate cancer was $6.5 \%$ (95\% CI, 6.2-6.7\%) for prostate cancer and 27.0\% (95\% CI, $26.5-27.4 \%$ ) for competing causes of death. Patients with well, moderately, or poorly differentiated disease respectively had 10-year cumulative mortality rates of $2.7 \%(95 \%$ CI, $2.3-3.2 \%), 4.3 \%$ (95\% CI, 4.1-4.5\%), and 15.1\% (95\% CI, $14.3-15.9 \%)$ for prostate cancer and $33.5 \%(95 \% \mathrm{CI}$, $32.2-34.8 \%$ ), 26.5\% (95\% CI, 26.0-26.9\%), and 29.0\% (95\% CI, 28.0-30.0\%) for competing causes of death.

Fig. (1) shows the estimated mortality curves for prostate cancer or competing causes of death among patients in each of the four primary treatment groups, stratified by age, grade, and stage at diagnosis. Prostate cancer mortality curves differed significantly across treatment groups among men $<80$ years with moderately or poorly differentiated disease (Table 3). However, no significant differences in prostate cancer mortality were found across treatment groups for men $<70$ years with well-differentiated disease or $\geq 80$ years with moderately or poorly differentiated disease (Table 3 ). The small number of prostate cancer deaths among men with well-differentiated disease and surgically treated men $\geq 80$ 


\section{A. Conservative Management}
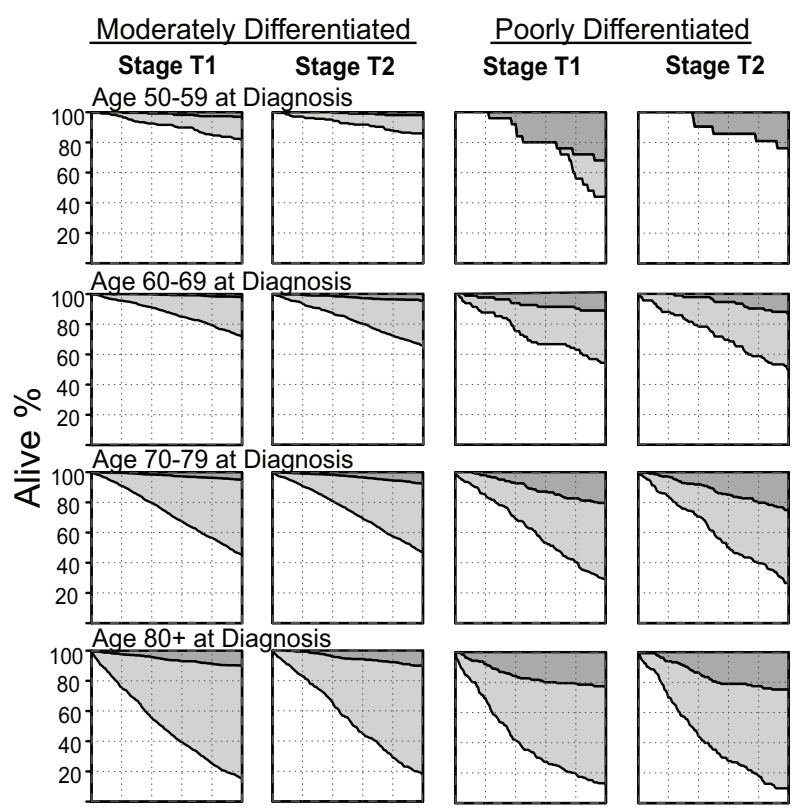

\section{Radiation Therapy}
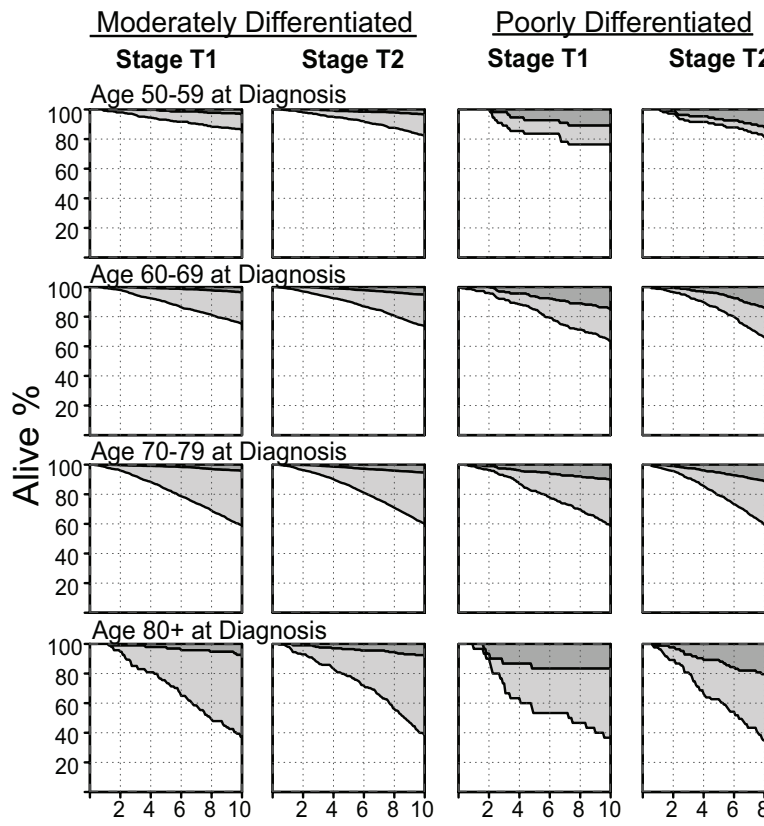

Stage T1 Stage T2
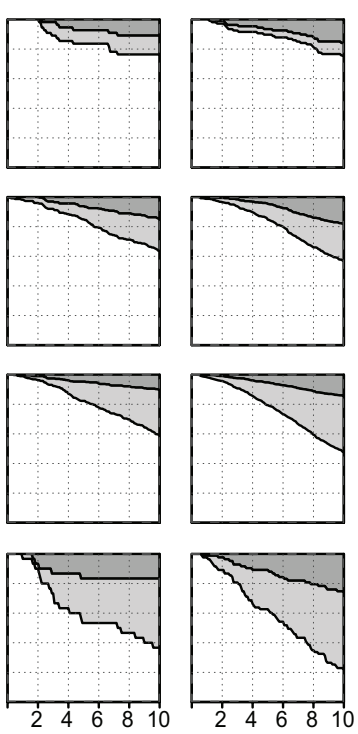

\section{B. ADT Monotherapy}

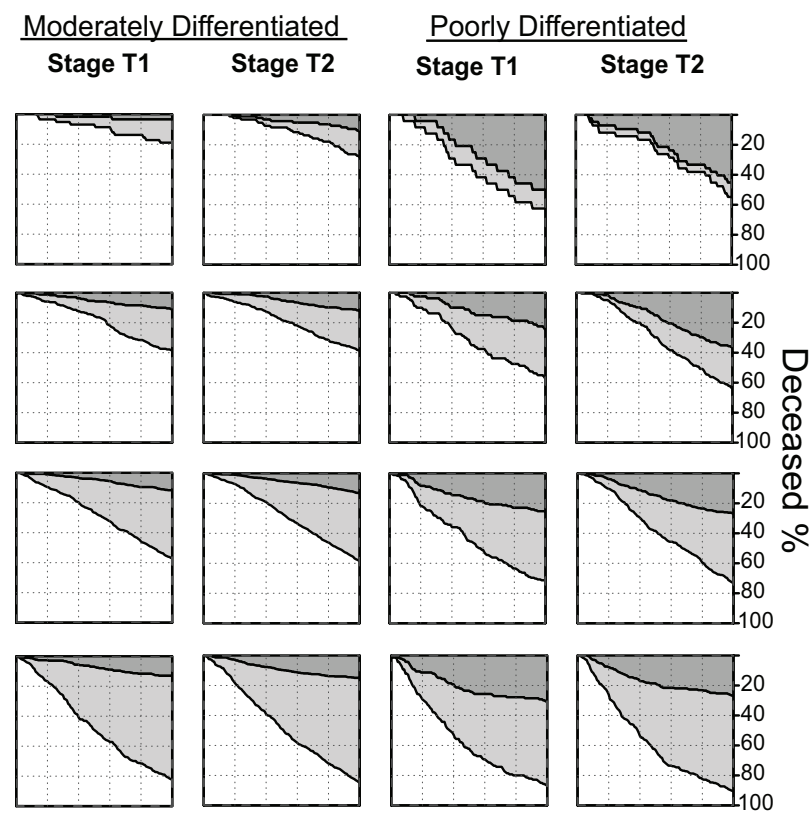

\section{Surgery}

Moderately Differentiated

Stage $\mathrm{T} 1$

Stage $\mathrm{T} 2$
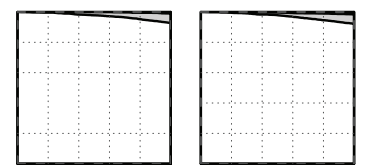

Poorly Differentiated

Stage T1 Stage T2
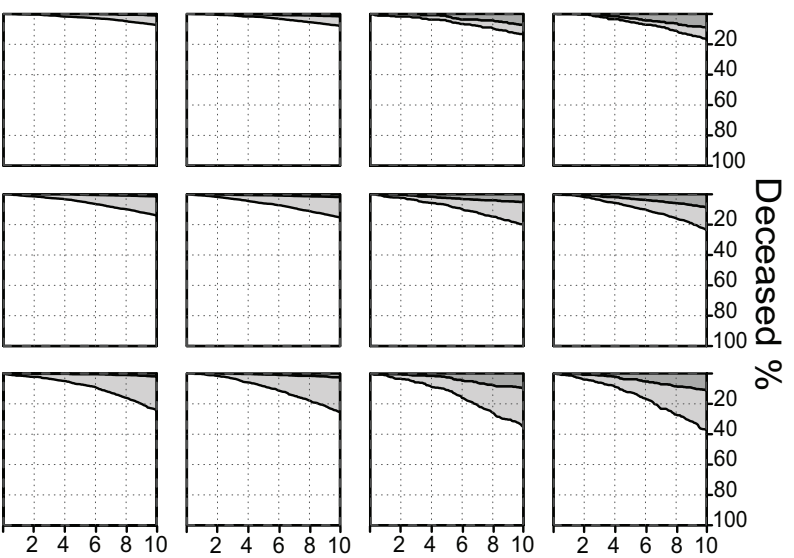

Fig. (1). Competing risk of death among men with localized prostate cancer who received primary treatment with conservative management (A), ADT monotherapy (B), radiation therapy $(\mathbf{C})$ or surgery $(\mathbf{D})$, stratified by age at diagnosis, tumor stage and grade. Prostate cancer mortality (dark grey), non-prostate cancer mortality (light grey), survival probability (white).

years limited the reliability of mortality estimates in these groups.

Prostate cancer mortality was highest among patients who received ADT monotherapy (Fig. 1B) across all strata, and was especially high among men $<70$ years diagnosed with poorly differentiated disease. Men who received ADT monotherapy or conservative management (Fig. 1A) both experienced relatively high mortality from causes other than their disease. Prostate cancer mortality was generally similar in men who received conservative management or radiotherapy (Fig. 1C), although men diagnosed at age $\geq 70$ or with poorly differentiated disease who were treated with radiotherapy tended to have lower mortality rates than those who received conservative management. Surgically treated men 
Table 3. Ten-year Disease-specific Cumulative Mortality (with 95\% Confidence Intervals) Among with Men with Localized Prostate Cancer Stratified by Primary Treatment, Age, Grade, and Stage at Diagnosis

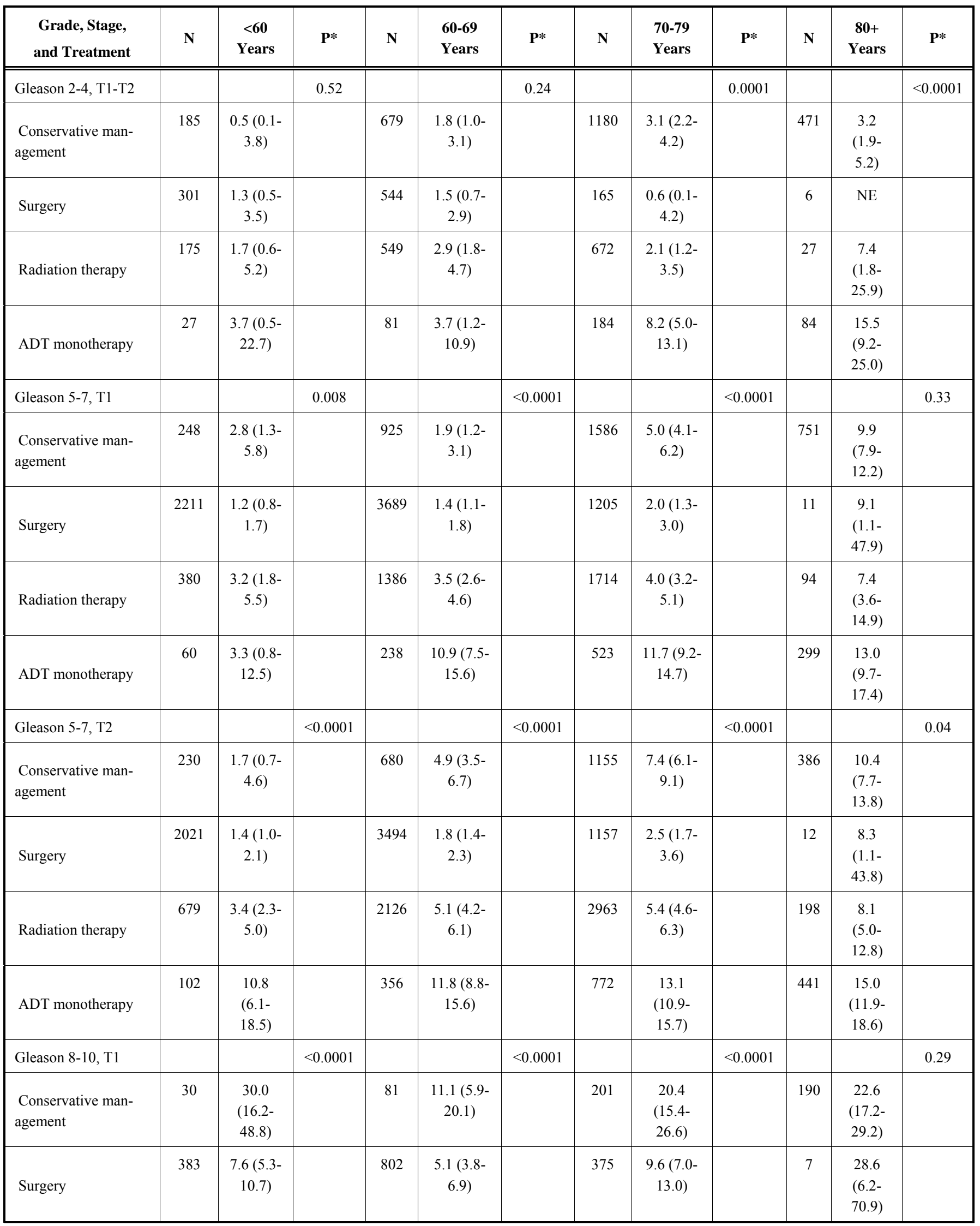


Table 3. Contd.....

\begin{tabular}{|c|c|c|c|c|c|c|c|c|c|c|c|c|}
\hline $\begin{array}{l}\text { Grade, Stage, } \\
\text { and Treatment }\end{array}$ & $\mathbf{N}$ & $\begin{array}{c}<60 \\
\text { Years }\end{array}$ & $\mathbf{P}^{*}$ & $\mathbf{N}$ & $\begin{array}{l}60-69 \\
\text { Years }\end{array}$ & $\mathbf{P}^{*}$ & $\mathbf{N}$ & $\begin{array}{l}70-79 \\
\text { Years }\end{array}$ & $\mathbf{P}^{*}$ & $\mathbf{N}$ & $\begin{array}{c}80+ \\
\text { Years }\end{array}$ & $\mathbf{P}^{*}$ \\
\hline Radiation therapy & 57 & $\begin{array}{l}10.5 \\
(4.8- \\
21.7)\end{array}$ & & 226 & $\begin{array}{r}14.6 \\
(10.6- \\
19.8)\end{array}$ & & 378 & $\begin{array}{c}10.3(7.6- \\
13.8)\end{array}$ & & 30 & $\begin{array}{l}16.7 \\
(7.0- \\
34.8)\end{array}$ & \\
\hline ADT monotherapy & 26 & $\begin{array}{c}53.8 \\
(34.4- \\
72.2)\end{array}$ & & 80 & $\begin{array}{c}25.0 \\
(16.7- \\
35.7)\end{array}$ & & 178 & $\begin{array}{c}25.3 \\
(19.4- \\
32.2)\end{array}$ & & 140 & $\begin{array}{c}30.7 \\
(23.6- \\
38.9)\end{array}$ & \\
\hline Gleason 8-10, T2 & & & $<0.0001$ & & & $<0.0001$ & & & $<0.0001$ & & & 0.64 \\
\hline $\begin{array}{l}\text { Conservative man- } \\
\text { agement }\end{array}$ & 25 & $\begin{array}{c}24.0 \\
(11.0- \\
44.7)\end{array}$ & & 92 & $\begin{array}{c}13.0(7.5- \\
21.7)\end{array}$ & & 207 & $\begin{array}{c}25.1 \\
(19.7- \\
31.5)\end{array}$ & & 133 & $\begin{array}{c}24.8 \\
(18.2- \\
32.9)\end{array}$ & \\
\hline Radiation therapy & 120 & $\begin{array}{c}18.3 \\
(12.4- \\
26.3)\end{array}$ & & 497 & $\begin{array}{c}18.3 \\
(15.1- \\
22.0)\end{array}$ & & 849 & $\begin{array}{c}14.1 \\
(11.9- \\
16.6)\end{array}$ & & 83 & $\begin{array}{c}25.3 \\
(17.0- \\
35.9)\end{array}$ & \\
\hline ADT monotherapy & 46 & $\begin{array}{c}45.7 \\
(31.8- \\
60.2)\end{array}$ & & 185 & $\begin{array}{c}36.2 \\
(29.6- \\
43.4)\end{array}$ & & 357 & $\begin{array}{c}26.6 \\
(22.3- \\
31.4)\end{array}$ & & 268 & $\begin{array}{c}26.9 \\
(21.9- \\
32.5)\end{array}$ & \\
\hline
\end{tabular}

*Global test of differences among the overall mortality curves for the four treatment groups

$\mathrm{NE}=$ not estimable

(Fig. 1D) had the lowest mortality from prostate cancer among men $<80$ years with moderately or poorly differentiated disease. Sensitivity analyses among men with pathologically confirmed localized disease following radical prostatectomy with lymph node dissection showed that prostate cancer mortality was slightly lower but similar to that for all surgically treated men (data not shown), indicating that misclassification of clinical stage did not have a substantial impact on the results.

\section{DISCUSSION}

Determining the optimal treatment of localized prostate cancer is a great challenge for physicians and patients, given limited evidence to date regarding the comparative effectiveness of treatment alternatives. In this population-based cohort of 45,440 California men with clinically localized prostate cancer, we found that patients who were initially treated with surgery, radiotherapy, ADT monotherapy, or conservative management differed significantly with respect to their ten-year risk of dying from prostate cancer or competing causes. To our knowledge, this large observational study is the first to compare mortality estimates among men with clinically localized prostate cancer treated with surgery, radiation, conservative management, as well as ADT monotherapy. This information provides a framework for understanding the expected long-term outcomes of localized prostate cancer given the initial treatment choice and practice patterns in the general population.
Although ADT monotherapy is not recommended for localized prostate cancer [6], it was received by $9.8 \%$ of the men in this cohort. This proportion was slightly higher than the estimate of $7.6 \%$ from a SEER Patterns of Care study (POC) in which treatment data from medical records was supplemented by forms sent to physicians for men diagnosed with localized disease in 1998 [21]. We found that combined therapy with ADT was utilized by $40.7 \%$ and $13.1 \%$ of patients treated with radiotherapy and surgery, respectively. A randomized trial of radiotherapy combined with ADT versus radiotherapy alone for localized prostate cancer reported that combined therapy significantly decreased disease-specific mortality [22]. In contrast, several randomized trials of neoadjuvant ADT before surgery have not shown a survival benefit [23-25], which may help explain the substantially greater frequency of ADT use among men treated with radiotherapy versus surgery. We found that men treated with ADT monotherapy had the highest disease-specific mortality across all strata of age, grade, and stage at diagnosis, consistent with previous studies including one randomized trial that did not find a survival benefit with ADT monotherapy $[7,26,27]$. It is possible that men treated with ADT monotherapy have higher-risk disease, contributing to poorer outcomes. However, in light of evidence that ADT is adversely associated with osteoporosis [28], cardiovascular disease and diabetes [29,30], and the lack of evidence of a survival benefit from ADT monotherapy, it is especially important for patients and physicians to be aware of the long-term outcomes among men in this group when considering treatment options. 
Approximately $70 \%$ of California men with localized prostate cancer underwent attempted curative treatment with surgery $(40.4 \%)$ or radiation $(29.1 \%)$. We found that men $<80$ years with moderately to poorly differentiated disease treated with surgery had the lowest mortality from prostate cancer. Patients $\geq 70$ years initially treated with radiotherapy versus conservative managment generally had lower diseasespecific mortality, although the differences were not significant among men $\geq 80$ years. These findings are consistent with evidence from randomized trials that treatment with surgery [9] or high-dose radiotherapy [31-35] improves outcomes of localized prostate cancer. In subgroup analyses from randomized trials, surgery significantly reduced overall and disease-specific mortality only among men $<65$ years [9], whereas radiation combined with ADT versus radiation alone significantly reduced disease-specific mortality only among men $\geq 70$ years [22]. Thus, evidence from both clinical trials and observational studies suggests that active treatment with radiotherapy may be more effective in older men, whereas surgery may be more effective in younger men [36]. Alternative explanations for the better outcomes among actively treated men include patient selection based on life expectancy $\geq 10$ years, absence of comorbidities that contraindicate treatment [6], or other unmeasured factors associated with improved prostate cancer survival.

We found no significant differences in prostate cancer mortality across treatment groups among men $<70$ with welldifferentiated disease or $\geq 80$ years with moderately or poorly differentiated disease, suggesting that conservative management is a safe and effective choice for these patients. The mortality estimates for California men who underwent initial conservative management was similar to U.S. men diagnosed with localized prostate cancer during 1992-2002 who were managed without surgery or radiation but may have received ADT within six months of diagnosis [37]. Studies of SEER treatment data for prostate cancer have shown that, whereas surgery and radiation are well captured $[38,39]$, hormonal therapy may be underascertained by medical record abstraction compared to patient self-report [40]. Thus, one potential limitation of the present study is that the conservative management group may include some men who received ADT. However, the similar proportion of men who received initial $\mathrm{ADT}$ monotherapy in this study compared to a SEER POC study in 1998 that supplemented registry data with physician surveys [21] suggests that the degree of ADT underascertainment by the CCR may be relatively modest. The high mortality from non-prostate cancer causes among men who initially received conservative management or ADT monotherapy may reflect high comorbidity contraindicating aggressive treatment. Greater comorbidity has been associated with higher overall mortality as well as lower prostate-cancer-specific mortality [41].

The main limitation of this observational study was that, without randomization, primary treatment groups may differ systematically with respect to unmeasured characteristics such as comorbidities that influence mortality. Thus, the data presented here are intended to describe mortality given a patient's initial treatment choice and practice patterns in the general population, and should not be interpreted as a quantification of treatment effects. Additionally, the CCR, like other SEER registries, does not have information on PSA values at diagnosis, and Gleason 5-7 tumors were collapsed as moderately differentiated disease, potentially obscuring survival differences in this group. The main strengths of this observational cohort study are the large sample size, followup for over ten years, and population-based setting, with capture of nearly all prostate cancer cases diagnosed in California. Thus, the findings are robust and broadly applicable, and are not restricted to specific clinics or age groups as is often the case for clinical trials or Medicare claims-based studies.

This study provides population-based estimates of a man's absolute risk of dying from prostate cancer or other causes within ten years of his diagnosis with localized prostate cancer depending upon his initial treatment choice and disease characteristics. These data may help patients and physicians to better understand the expected long-term outcomes of clinically localized prostate cancer in the context of practice patterns in the general population. Additional studies will be needed to characterize mortality trends as practice patterns change over time.

\section{CONFLICT OF INTEREST}

The authors confirm that this article content has no conflicts of interest.

\section{ACKNOWLEDGEMENTS}

We thank David Johnston and Tammi Nicosia for programming and graphics assistance. This study was supported by the California State Department of Public Health; National Cancer Institute (NCI) Surveillance Epidemiology and End Results Program contracts HHSN261201000040C, HHSN261201000035C and HHSN261201000034C; Centers for Disease Control and Prevention, National Program of Cancer Registries U58DP000807; and NCI K07CA143047 (WS). The ideas and opinions expressed herein are those of the authors and endorsement by the State of California Department of Public Health, NCI, and the Centers for Disease Control and Prevention or their contractors and subcontractors is not intended nor should be inferred. The authors have no conflicts of interest, including specific financial interests and relationships and affiliations relevant to the subject of this manuscript.

\section{REFERENCES}

[1] Cooperberg MR, Broering JM, Litwin MS, et al. The contemporary management of prostate cancer in the United States: lessons from the cancer of the prostate strategic urologic research endeavor (CapSURE), a national disease registry. J Urol 2004; 171: 1393401.

[2] Siegel R, Naishadham D, Jemal A. Cancer statistics, 2012. CA Cancer J Clin 2012; 62: 10-29.

[3] Andriole GL, Crawford ED, Grubb RL, et al. Prostate cancer screening in the randomized Prostate, Lung, Colorectal, and Ovarian Cancer Screening Trial: mortality results after 13 years of follow-up. J Natl Cancer Inst 2012; 104: 125-32.

[4] Schroder FH, Hugosson J, Roobol MJ, et al. Prostate-cancer mortality at 11 years of follow-up. N Engl J Med 2012; 366: 981 90.

[5] Smith MR. Effective treatment for early-stage prostate cancer-possible, necessary, or both? N Engl J Med 2011; 364: 1770-2.

[6] Mohler J, Bahnson RR, Boston B, et al. NCCN clinical practice guidelines in oncology: prostate cancer. J Natl Compr Canc Netw 2010; 8: 162-200. 
[7] Wong YN, Freedland SJ, Egleston B, et al. The role of primary androgen deprivation therapy in localized prostate cancer. Eur Urol 2009; 56: 609-16.

[8] Cooperberg MR, Carroll PR, Klotz L. Active surveillance for prostate cancer: progress and promise. J Clin Oncol 2011; 29 (27): 3669-76.

[9] Bill-Axelson A, Holmberg L, Ruutu M, et al. Radical prostatectomy versus watchful waiting in early prostate cancer. $\mathrm{N}$ Engl J Med 2011; 364: 1708-17.

[10] Wilt TJ, Brawer MK, Jones KM, et al. Radical prostatectomy versus observation for localized prostate cancer. N Engl J Med 2012; 367: 203-13.

[11] Dall'Era MA, Konety BR. Active surveillance for low-risk prostate cancer: selection of patients and predictors of progression. Nat Clin Pract Urol 2008; 5: 277-83.

[12] Derweesh IH, Kupelian PA, Zippe C, et al. Continuing trends in pathological stage migration in radical prostatectomy specimens. Urol Oncol 2004; 22: 300-6

[13] Albertsen PC, Walters S, Hanley JA. A comparison of cause of death determination in men previously diagnosed with prostate cancer who died in 1985 or 1995. J Urol 2000; 163: 519-23.

[14] Penson DF, Albertsen PC, Nelson PS, Barry M, Stanford JL. Determining cause of death in prostate cancer: are death certificates valid? J Natl Cancer Inst 2001; 93: 1822-3.

[15] Fritz A, Ries L, Eds. SEER Extent of Disease -- 1988 Codes and Coding Instructions. $3^{\text {rd }}$ ed. Bethesda, MD: National Cancer Institute 1988

[16] Gomez SL, Le GM, West DW, Satariano WA, O'Connor L. Hospital policy and practice regarding the collection of data on race, ethnicity, and birthplace. Am J Public Health 2003; 93: 16858 .

[17] Yost K, Perkins C, Cohen R, Morris C, Wright W. Socioeconomic status and breast cancer incidence in California for different race/ethnic groups. Cancer Causes Control 2001; 12: 703-11.

[18] Fine JP, Gray RJ. A proportional hazards model for the subdistribution of a competing risk. J Am Stat Assoc 1999; 94: 496-509.

[19] Gray RJ. A class of k-sample tests for comparing the cumulative incidence of a competing risk. Ann Stat 1988; 16: 1141-54.

[20] Oehlert GW. A note on the delta method. Am Stat 1992; 46: 27-9.

[21] Hamilton AS, Albertsen PC, Johnson TK, et al. Trends in the treatment of localized prostate cancer using supplemented cancer registry data. BJU Int 2011; 107: 576-84.

[22] Jones CU, Hunt D, McGowan DG, et al. Radiotherapy and shortterm androgen deprivation for localized prostate cancer. N Engl J Med 2011; 365: 107-18

[23] Yee DS, Lowrance WT, Eastham JA, et al. Long-term follow-up of 3-month neoadjuvant hormone therapy before radical prostatectomy in a randomized trial. BJU Int 2010; 105: 185-90.

[24] Soloway MS, Pareek K, Sharifi R, et al. Neoadjuvant androgen ablation before radical prostatectomy in $\mathrm{cT} 2 \mathrm{bNxMo}$ prostate cancer: 5-year results. J Urol 2002; 167: 112-6.
[25] Debruyne FM, Witjes WP. Neoadjuvant hormonal therapy prior to radical prostatectomy: the European experience. Mol Urol 2000; 4 : 251-6.

[26] Lu-Yao GL, Albertsen PC, Moore DF, et al. Survival following primary androgen deprivation therapy among men with localized prostate cancer. JAMA 2008; 300: 173-81.

[27] McLeod DG, Iversen P, See WA, et al. Bicalutamide $150 \mathrm{mg}$ plus standard care vs standard care alone for early prostate cancer. BJU Int 2006; 97: 247-54.

[28] Shahinian VB, Kuo YF, Freeman JL, Goodwin JS. Risk of fracture after androgen deprivation for prostate cancer. N Engl J Med 2005; 352: $154-64$

[29] Saylor PJ, Smith MR. Adverse effects of androgen deprivation therapy: defining the problem and promoting health among men with prostate cancer. J Natl Compr Canc Netw 2010; 8: 211-23.

[30] Keating NL, O'Malley AJ, Smith MR. Diabetes and cardiovascular disease during androgen deprivation therapy for prostate cancer. J Clin Oncol 2006; 24: 4448-56.

[31] Beckendorf V, Guerif S, Le Prise E, et al. 70 Gy versus 80 Gy in localized prostate cancer: 5 -year results of GETUG 06 randomized trial. Int J Radiat Oncol Biol Phys 2011; 80: 1056-63.

[32] Zietman AL, Bae K, Slater JD, et al. Randomized trial comparing conventional-dose with high-dose conformal radiation therapy in early-stage adenocarcinoma of the prostate: long-term results from proton radiation oncology group/american college of radiology 9509. J Clin Oncol 2010; 28: 1106-11.

[33] Kuban DA, Tucker SL, Dong L, et al. Long-term results of the M. D. Anderson randomized dose-escalation trial for prostate cancer. Int J Radiat Oncol Biol Phys 2008; 70: 67-74.

[34] Al-Mamgani A, van Putten WL, Heemsbergen WD, et al. Update of Dutch multicenter dose-escalation trial of radiotherapy for localized prostate cancer. Int J Radiat Oncol Biol Phys 2008; 72: 980-8.

[35] Dearnaley DP, Sydes MR, Graham JD, et al. Escalated-dose versus standard-dose conformal radiotherapy in prostate cancer: first results from the MRC RT01 randomised controlled trial. Lancet Oncol 2007; 8: 475-87.

[36] Abdollah F, Sun M, Thuret R, et al. A competing-risks analysis of survival after alternative treatment modalities for prostate cancer patients: 1988-2006. Eur Urol 2011; 59: 88-95.

[37] Lu-Yao GL, Albertsen PC, Moore DF, et al. Outcomes of localized prostate cancer following conservative management. JAMA 2009; 302: $1202-9$.

[38] Cooper GS, Virnig B, Klabunde CN, et al. Use of SEER-Medicare data for measuring cancer surgery. Med Care 2002; 40: IV-43-8.

[39] Virnig BA, Warren JL, Cooper GS, et al. Studying radiation therapy using SEER-Medicare-linked data. Med Care 2002; 40: IV49-54.

[40] Clegg LX, Potosky AL, Harlan LC, et al. Comparison of selfreported initial treatment with medical records: results from the prostate cancer outcomes study. Am J Epidemiol 2001; 154: 582-7.

[41] Albertsen PC, Moore DF, Shih W, et al. Impact of comorbidity on survival among men with localized prostate cancer. J Clin Oncol 2011; 29: 1335-41 